\section{Celebrating Years}

${ }^{1}$ Dr. Syeda Mehnaz

Junior Consultant of Paediatrics Kurmitola General Hospital, Dhaka

${ }^{2}$ Prof. Dr. M A K Azad Chowdhury Professor and Head

Dept. of Neonatology

BICH \& Dhaka Shishu Hospital

3 Prof. Dr. B H Nazma Yasmeen

Professor and Head

Dept. of Paediatrics

Northern International Medical

College, Dhaka

${ }^{4}$ Dr. Md. Masudur Rahman

Junior Consultant of

Orthopaedic Surgery

Faridpur Medical College Hospital

${ }^{5}$ Dr. Rowshan Jahan Akter

Assistant Professor of

Paediatrics

Dhaka Shishu (Children) Hospital

${ }^{6}$ Dr. Manifa Afrin

Assist. Professor of Paediatrics

BIHS General Hospital

Darus Salam, Mirpur, Dhaka

${ }^{7}$ Dr. Mahmuda Begum

Junior Consultant of Paediatrics

Keranigonj UHC, Dhaka

Correspondence

Dr. Syeda Mehnaz

MBBS, MD (Paediatrics)

Junior Consultant of Paediatrics

Kurmitola General Hospital

Kurmitola, Dhaka

e-mail: mehnaz.masud@gmail.com

\title{
Role of Human Recombinant Erythropoietin (rHuEPO) in Perinatal Asphyxia-a randomized controlled trial
}

\author{
S Mehnaz ${ }^{1}$, M A K A Chowdhury ${ }^{2}$, B H N Yasmeen ${ }^{3}$, M M Rahman ${ }^{4}$, R J Akhter ${ }^{5}$, \\ M Afrin ${ }^{6}$, M Begum $^{7}$
}

\section{Abstract}

Background : Perinatal asphyxia is an insult to the fetus or newborn infant due to lack of oxygen (hypoxia) and/or a lack of perfusion (ischemia) to various organs, which will manifest as difficulty in establishing spontaneous respiration evident by delayed cry after birth, at least after one minute. World-wide, perinatal asphyxia accounts for about 900,000 deaths each year. In Bangladesh it is a major cause of neonatal death. A substantial proportion of the children that survive suffer late effects such as cerebral palsy and epilepsy.

Objective : To determine the efficacy of erythropoietin in improving the neurological outcome of term neonates with perinatal asphyxia (HIE stage II and III).

Materials and methods : A Randomized Controll Trial was carried out in the Neonatal ward and NICU of Dhaka Shishu Hospital from 1st April 2014 to 30th Sep 2015. A total 68 neonates with perinatal asphyxia (both HIE stage II and III) who fulfill the inclusion criteria were enrolled and randomly assigned to intervention group $(n=35)$ and control group ( $\mathrm{n}=33$ ). Intervention group received rHuEPO 300-500 U/kg/dose daily subcutaneously for 5 days within first 48 hours of birth along with the standard treatment protocol and control group received standard treatment protocol only.

Results : Baseline clinical characteristics, USG of brain during hospital stay were almost similar in both groups. Statistically significant effect was noted in seizure control, tolerance of oral feeding, hospital stay and neurological outcome at 3 months of age ( $p=008)$. USG of brain at 3 months of age also improved significantly ( $p=0.027$ ).

Conclusion : This study demonstrates the effectiveness of early administration of rHuEPO to term neonates with moderate to severe asphyxia, beneficial effect on short term outcomes like seizure control, tolerance of oral feeding and neurological outcome at 3 months of age.

A large multicenter study would be done for further evaluation of these findings.

Key words : Erythropoietin, Perinatal asphyxia, HIE stage II and III.

DOI: 10.3329/nimcj.v10i1.39326

Northern International Medical College Journal Vol. 10 No. 1 July 2018, Page 330-334

\section{Introduction}

Perinatal asphyxia is an important cause of acute neurologic injury, occurring in 2 to 3 cases per 1000 term live births in developed countries, with a higher incidence in less developed countries including Bangladesh. ${ }^{1}$

Acute neurologic injury i.e. Hypoxic-ischemic encephalopathy (HIE) is an important cause of death and disability in full-term infants. The incidence of moderate or severe hypoxicischemic encephalopathy has remained essentially unchanged over the past 20 years, at 1.5 to 2 per 1000 live births in the United States.
Approximately 15 to 20 percent of these infants will die, and 20 to 25 percent of those who survive will be disabled. ${ }^{2,3}$

The mechanisms that cause neurological damage (hypoxic-ischemic encephalopathy) after perinatal asphyxia are divided schematically into three metabolic phases and the objective of the treatment is to limit ongoing damage to cell. ${ }^{4-6}$

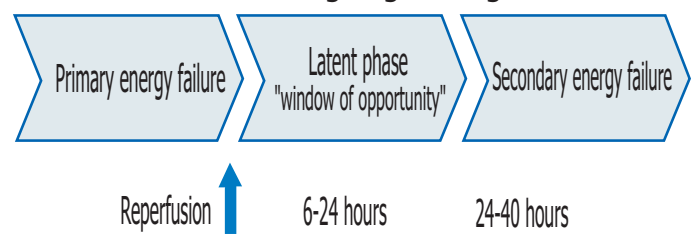


Hypoxia leads to Phase 1 primary energy failure.

Phase 2, Laten Phase - A short time after reoxygenation, aerobic metabolism and cell functions are reestablished. However, as a result of a cascade of cellular mechanisms, ${ }^{7,8}$ after this «latent phase» of 6-24 hours mitochondrial energy production again begins to fail.

Phase 3- Secondary energy failure lasts for 24-48 hours after the hypoxic event. The damage that occurs during this phase is considerable. $^{9}$

Neuroprotective treatment targeting the «latent phase» may limit the secondary neuron damage due to perinatal asphyxia. ${ }^{5}$

Erythropoietin (EPO) is a haematopoietic hormone that also has receptors in the brain, ${ }^{10}$ having an anti-inflammatory effect, EPO can reduce brain damage after hypoxia through reduced nitric oxide (NO) production, ${ }^{11}$ inhibited glutamate toxicity ${ }^{12}$ and reduced lipid peroxidation. ${ }^{13}$ Neuronal anti-apoptotic mechanisms, angiogenesis and neurogenesis are also stimulated and modulated. ${ }^{14}$

Erythropoietin (EPO) as a neuroprotective agent has been studied extensively both in animal and human. Erythropoietin and its receptors were up regulated following hypoxic injury and were correlated positively with outcomes. Studies have demonstrated anti apoptotic action in neurons following hypoxic injury where NO levels were reduced with the use EPO. ${ }^{15}$

Some previous studies occur in Romania, Japan, China and USA proved that Erythropoietin is neuroprotective with minimal side effects but there is no clinical trial in Bangladesh. Our study the role of erythropoietin in improving the neurological outcome of term neonates with perinatal asphyxia is probably the first research work in Bangladesh. Therefore, this study will help us to evaluate the effectiveness of erythropoietin in perinatal asphyxia with HIE stage II and III.

\section{Materials and methods}

A Randomized Controlled Trial was carried out in the Neonatal ward and NICU of Dhaka Shishu Hospital from $1^{\text {st }}$ April 2014 to $30^{\text {th }}$ Sep 2015. Neonates eligible for the study had

- gestational age $>37$ weeks

- age $>48$ hours at the time of admission

- weight $>2.5 \mathrm{~kg}$

- HIE stage-moderate (II) or severe (III) assessed by Sarnat and Sarnat staging.

Baby with IUGR, age $>48$ hours, haemolytic disease, congenital malformation along with maternal eclampsia and diabetes were excluded from the study.

In this study period total 142 neonates were assessed for eligibility. Out of them 68 eligible neonates were enrolled according to inclusion criteria. These 68 asphyxiated neonates were randomly assigned to Intervention group, (Case, $\mathrm{n}=35$ ) who received rHuEPO $300-500 \mathrm{U} / \mathrm{kg} /$ dose daily subcutaneously for 5 days within first 48 hours of birth along with the standard treatment protocol and Control group, $(n=33)$ who received standard treatment according to the unit protocol for perinatal asphyxia.

The erythropoietin dose (500 IU/ $\mathrm{kg} /$ dose) for 5 days was based on studies by Zhu et al ${ }^{14}$ and Elmahdy et al. ${ }^{15}$

The neonates were monitored for short term outcomes such as 1) seizure control 2) tolerance of oral feeding 3) duration of hospital stay 4) neurological assessment done at 1 and 3 months of age 5) USG of brain were done on admission and at 3 months of age.

The administration of rHuEPO was carried out by the Principal investigator. During the first 72 hours of life heart rate, respiratory rate, blood pressure, temperature and other clinical parameter were monitored routinely. Clinical assessments including neurological status were done at admission and during hospital stay, the grade of HIE (moderate or severe), the type of respiratory support needed, the presence of seizures and time of initiation of oral feeding.

Prognosis (Physical and neurological) were assessed clinically by developmental assessment (gross and fine motor examination, vision, hearing, cognition and assessment of muscle tone) and neurosonogram with 2 follow up at 1 and 3 months.

Renal function test, Liver function test and EEG were done as required.

The data was analyzed according to standard procedure. SPSS Win version 17 programs have been used for data analysis. Results of the findings was verified by doing standard test for significance like Unpaired student " $t$ " test and Chi-Square $\left(X^{2}\right)$ tests and finding out the ${ }_{P}$ value. Statistically significant ${ }_{P}$ value considered if ${ }_{P}$ was $<0.05$.

The Ethical Review Committee of BICH, Dhaka Shishu Hospital approved the study.

\section{Results}

During the study period total 142 neonates were assessed for eligibility. Out of them 68 eligible neonates were enrolled. They randomized in two groups, 35 in Intervention and 33 in Control Group. After enrolment 8 patients ( 5 in Intervention group and 3 in Control Group) had given discharge on risk bond and 5 patients ( 2 in Intervention group and 3 in Control Group) had died.

Finally, 55 neonates completed the study, 28 neonates in Intervention Group and 27 in Control Group. Results of baseline characteristics and outcome are shown in different tables and figures.

Sex distribution shows that in case group male were 15 (53.6\%) and $16(59.3)$ in control group, female were $13(46.4 \%)$ in case 
group and $11(40.7 \%)$ in control group. Statistically the sex distribution between groups was not significant.

Mean $( \pm S D)$ birth weight of the case and control group of neonates were $2.83 \pm 0.23$ (range 2.60-3.20) and 2.78 \pm 0.19 (range $2.50-3.10) \mathrm{kg}$, respectively. The mean difference of the birth weight was not statistically significant.

Mean $( \pm S D)$ Apgar score at 5 minute of the case and control group of neonates was $4.87 \pm 1.04$ (range 3-6) and $4.40 \pm 0.84$ (range 3-6) respectively. The mean difference between 2 groups was statistically not significant (Table- I).

Table-I : Baseline data of the neonates

\begin{tabular}{|c|c|c|c|}
\hline $\begin{array}{l}\text { Parameters } \\
\text { Sex }\end{array}$ & $\begin{array}{c}\text { Case }(n=28) \\
\text { No }(\%)\end{array}$ & $\begin{array}{c}\text { Control(n=27) } \\
\text { No. }(\%)\end{array}$ & P value \\
\hline $\begin{array}{l}\text { Male } \\
\text { Female }\end{array}$ & $\begin{array}{l}15(53.6) \\
13(46.4)\end{array}$ & $\begin{array}{c}16(59.3) \\
11(40.7)\end{array}$ & $0.439^{\mathrm{ns}}$ \\
\hline \multicolumn{4}{|c|}{ Birth weight (kg) } \\
\hline $\begin{array}{l}\text { Mean } \pm \text { SD } \\
\text { Range }\end{array}$ & $\begin{array}{c}2.83 \pm 0.23 \\
2.60-3.20\end{array}$ & $\begin{array}{l}2.78 \pm 0.19 \\
2.50-3.10\end{array}$ & $0.399^{\text {ns }}$ \\
\hline \multicolumn{4}{|c|}{ Apgar score at 5 minute } \\
\hline $\begin{array}{c}\text { Mean } \pm S D \\
\text { Range }\end{array}$ & $\begin{array}{c}4.87 \pm 1.04 \\
3.00-6.00\end{array}$ & $\begin{array}{c}4.40 \pm 0.89 \\
3.00-6.00\end{array}$ & $0.068^{\mathrm{ns}}$ \\
\hline
\end{tabular}

Mean ( \pm SD) gestational age of case and control groups was $37.87 \pm 0.90$ (range 37-40) and 37.80 \pm 0.66 (range 37-39) weeks respectively. The mean difference between 2 groups was not statistically significant.

Status of mode of delivery showed that vaginal delivery was achieved in $23(82.1 \%)$ and $25(92.6 \%)$ and Caesarean section was required in $5(17.9 \%)$ and $2(7.4 \%)$ in case and control group respectively. Statistical analysis showed no significant variation (Table-II).

\begin{tabular}{|c|c|c|c|c|c|}
\hline \multirow{2}{*}{\multicolumn{2}{|c|}{$\begin{array}{l}\text { Parameters Case }(\mathbf{n}=28) \\
\text { No }(\%)\end{array}$}} & & \multicolumn{2}{|c|}{$\begin{array}{c}\text { Control }(n=27) \\
\text { No. }(\%)\end{array}$} & \multirow[t]{2}{*}{${ }_{P}$ value } \\
\hline & & & & & \\
\hline \multicolumn{2}{|c|}{ Mean \pm SD $\quad 37.87 \pm 0.90$} & & \multirow{2}{*}{\multicolumn{2}{|c|}{$\begin{array}{l}37.80 \pm 0.66 \\
37.00-39.00\end{array}$}} & \multirow[t]{2}{*}{$0.745^{\mathrm{ns}}$} \\
\hline \multicolumn{2}{|c|}{ Range $\quad 37.00-40.00$} & & & & \\
\hline Mode of delivery & No. & $(\%)$ & No. & $(\%)$ & \\
\hline Vaginal & 23 & $(82.1)$ & 25 & $(92.6)$ & $0.226^{\mathrm{ns}}$ \\
\hline $\mathrm{CS}$ & 5 & $(17.9)$ & 2 & $(7.4)$ & \\
\hline
\end{tabular}

HIE stage of perinatal asphyxia in case and control groups respectively showed that $26(92.9 \%)$ and $24(88.9 \%)$ were in stage II and $2(7.1 \%)$ and $3(11.1 \%)$ were in stage III. Statistical analysis showed no significant variation (Table- VI).

Mean $( \pm S D)$ age of the neonates at onset of convulsion was $12.60 \pm 10.30$ (range 1-24) hours in case and $13.73 \pm 20.20$ (rage 1-72) hours in control group respectively. The mean difference was statistically not significant (Table-III).
Table-III : Baseline status of perinatal asphyxia

\begin{tabular}{|c|c|c|c|}
\hline Parameters & $\begin{array}{c}\text { Case }(\mathbf{n}=28) \\
\text { No }(\%)\end{array}$ & $\begin{array}{c}\text { Control }(n=27) \\
\text { No. }(\%)\end{array}$ & ${ }_{P}$ value \\
\hline \multicolumn{4}{|c|}{ Perinatal asphyxia with HIE stage } \\
\hline Stage II & $26(92.9)$ & $24(88.9)$ & $0.482^{\mathrm{ns}}$ \\
\hline Stage III & $2(7.1)$ & $3(11.1)$ & \\
\hline \multicolumn{4}{|c|}{ Age at onset of convulsion (hour) } \\
\hline Mean \pm SD & $12.60 \pm 10.30$ & $13.73 \pm 20.70$ & $.789^{\text {ns }}$ \\
\hline Range & $1.00-24.00$ & $1.00-72.00$ & \\
\hline
\end{tabular}

USG finding of the neonates on admission was normal in 9 (32.1\%) and $5(18.5 \%)$ and abnormal in 19(67.9\%) and 22 $(81.5 \%)$ in case and control group respectively. Statistical analysis did not show any significant variation (Table- IV).

Table- IV : USG finding of Brain on admission

\begin{tabular}{lllcll} 
Parameters & \multicolumn{2}{c}{ Case $(\mathbf{n = 2 8})$} & \multicolumn{2}{c}{ Control(n=27) } & Palue \\
& No & $(\%)$ & No. & $(\%)$ & \\
Normal & 9 & $(32.1)$ & 5 & $(18.5)$ & $0.198^{\text {ns }}$ \\
Abnormal & 19 & $(67.9)$ & 22 & $(81.5)$ &
\end{tabular}

Table-V shows immediate outcome. Mean ( \pm SD) time taken to control neonatal seizure was $39.93 \pm 24.00$ (range 3-72) hours and $66.73 \pm 50.54$ (range 7-168) hours in case and control group respectively. The mean difference was statistically significant $(\boldsymbol{P}<0.05)$.

Feeding start by the neonates were $2-3$ days in $13(46.4 \%)$ and $5(18.5 \%) ; 4-5$ days in $10(35.7 \%)$ and $5(18.5 \%)$; and $>5$ days in $5(17.9 \%)$ and $17(63.0 \%)$ neonates in case and control group respectively. The variation was statistically significant.

Mean $( \pm S D$ ) hospital stay of neonates was 6.93 \pm 1.91 (range 510) days for case group and $9.13 \pm 2.87$ (range 3-14) days for control group. The mean difference of hospital stay was statistically significant (Table- V).

Table-V : Immediate neurological outcome

\begin{tabular}{|c|c|c|c|c|c|}
\hline \multicolumn{5}{|c|}{$\begin{array}{l}\text { Parameters Case }(n=28) \quad \text { Control }(n=27) \\
\text { Time taken to control seizure (hour) }\end{array}$} & \multirow{2}{*}{$\begin{array}{c}\boldsymbol{P}^{\text {value }} \\
0.011^{*}\end{array}$} \\
\hline Mean \pm SD & \multicolumn{2}{|c|}{$39.93 \pm 24.00$} & \multicolumn{2}{|l|}{$66.73 \pm 50.54$} & \\
\hline \multirow[t]{2}{*}{ Range } & \multicolumn{2}{|l|}{$3.00-72.00$} & \multicolumn{2}{|l|}{$7.00-168.00$} & ( $\mathrm{t}$ test) \\
\hline & $\begin{array}{l}\text { No. } \\
\text { g (day) }\end{array}$ & $(\%)$ & No. & $(\%)$ & \\
\hline $2-3$ & 13 & $(46.4)$ & 5 & $(18.5)$ & \multirow{3}{*}{$\begin{array}{l}0.003^{* *} \\
\left(X^{2} \text { test }\right)\end{array}$} \\
\hline $4-5$ & 10 & (35.7) & 5 & (18.5) & \\
\hline$>5$ & 5 & (17.9) & 17 & $(63.0)$ & \\
\hline \multicolumn{6}{|c|}{ Duration of hospital stay (days) } \\
\hline Mean \pm SD & $6.93 \pm 1.91$ & & $9.13 \pm 2.87$ & & $0.001^{* *}$ \\
\hline Range & $5.00-10.00$ & & $3.00-14.00$ & & ( $\mathrm{t}$ test) \\
\hline
\end{tabular}

USG finding of the neonates after 3 months, was normal in 23 $(88.5 \%)$ and $14(60.9 \%)$ and abnormal in $3(11.5 \%)$ and 9 $(39.1 \%)$ in case and control group respectively. Statistically significant variation was observed (Table- VI).

Table- VI : USG finding of Brain after 3 months

\begin{tabular}{lccccc} 
& \multicolumn{2}{c}{ Case $(\mathbf{n}=\mathbf{2 6})$} & \multicolumn{2}{c}{ Control $(\mathbf{n}=\mathbf{2 3})$} & \multirow{2}{*}{ value } \\
No. & $\mathbf{( \% )}$ & No. & $\mathbf{( \% )}$ & \\
Normal & 23 & $(88.5)$ & 14 & $(60.9)$ & $0.027^{*}$ \\
Abnormal & 3 & $(11.5)$ & 9 & $(39.1)$ &
\end{tabular}


Out of 26 neonates of case group, 19 (73.1\%) were neurologically normal and 7 (26.9\%) had abnormal neurological findings.

Out of 23 neonates of control group, 9 (39.1\%) were neurologically normal and $14(60.9 \%)$ showed abnormal neurological findings. Statistically significant variation was observed (Table-VII).

Table-VII : Neurological outcome after one month

\begin{tabular}{lccccc} 
& \multicolumn{2}{c}{ Case $(\mathbf{n = 2 6 )}$} & \multicolumn{2}{c}{ Control $(\mathbf{n = 2 3 )}$} & \multirow{P}{*}{ value } \\
& No. & $\mathbf{( \% )}$ & No. & $\mathbf{( \% )}$ & \\
Normal & 19 & $(73.1)$ & 9 & $(39.1)$ & $0.017^{*}$ \\
Abnormal & 7 & $(26.9)$ & 14 & $(60.9)$ & (Chi-square)
\end{tabular}

Out of 26 neonates of case group, 21 (80.8\%) were neurologically normal and $5(19.2 \%)$ had abnormal neurological findings.

Out of 23 neonates of control group, 10 (43.5\%) were neurologically normal and $13(56.5 \%)$ showed abnormal neurological findings. Statistically significant variation was observed (Table- VIII)

Table- VIII : Neurological outcome after 3 month

\begin{tabular}{lccccc} 
Outcome & \multicolumn{2}{c}{ Case $(\mathbf{n = 2 6 )}$} & \multicolumn{2}{c}{ Control $(\mathbf{n}=\mathbf{2 3})$} & P value \\
& No. & $\mathbf{( \% )}$ & No. & $\mathbf{( \% )}$ & \\
Normal & 21 & $(80.8)$ & 10 & $(43.5)$ & $0.008^{*}$ \\
Abnormal & 5 & $(19.2)$ & 13 & $(56.5)$ & (Chi-square)
\end{tabular}

\section{Discussion}

Few studies have been done worldwide on the neuroprotective effects of Epo on human infants with HIE. The first study by Zhu et $\mathrm{al}^{16}$ in 2009 compared Epo to supportive care in infants with moderate-to-severe encephalopathy. The study concluded that EPO reduced the risk of disability for infants with moderate HIE, without side effects.

In this study baseline characteristics (neonate and mother) of both the groups were found similar which was consistent with the study of Pradeep KB et al. and Elmahdy H. ${ }^{17,18}$

Outcome variables such as initiation of oral feeds, duration of seizure control, duration of hospital stay and neurological outcome at 1 and 3 months of age were based on the study conducted by Kumar $\mathrm{P}$ et al. ${ }^{15}$

In our study we observed that the seizures lasted for a longer duration in control group (median of 66 hours) compared to intervention group (median of 39 hours). The $p$ value was significant $(p=0.011)$. This results consistent with the previous study done by Elmahdy et al ${ }^{18}$ and Kumar $\mathrm{P}$ et al. ${ }^{15}$

Reaching oral feeds (sucking) within 5-7 days was one of the short term neurological outcomes suggesting oromotor coordination in asphyxiated newborns study done by Bhat et al. ${ }^{19}$
In our study to see this effect, babies were initiated on tube feeds after assessing the gut function (absence of nasogastric aspirates or abdomen distension) which was gradually increased as per the tolerance.

Once the babies were hemodynamically stable, they were assessed for oromotor coordination (suck and swallow) and started on cup \& spoon feeds. This study shown significant improvement on initiation of oral feeding in treatment group than control group. This correlated with previous study done by Kumar $\mathrm{P}$ et al. ${ }^{15}$

Mean duration of hospital stay in treatment and control group is $6.93 \pm 1.91$ and $9.13 \pm 2.87$, the difference is statistically significant. There is no significant difference in USG of brain findings in treatment and control group on admission $(\boldsymbol{P}>.05)$.

USG was performed on 49 follow up patients. Among them $23(88.5 \%)$ out of 26 in treatment group found normal findings in comparison to $14(60.9 \%)$ out of 23 in control group. The difference is statistically significant and correlated with previous study done by Bhat et al. ${ }^{19}$

This study also showed that erythropoietin is neuroprotective that was reflected by fewer neonates with neurologic abnormalities in intervention group. The neurological outcome of study population at 1 month showed $19(73.1 \%)$ normal out of 26 in treatment group and 9 (39.1\%) out of 23 in control group, the findings are statistically significant.

At 3 months the neurological outcome was normal 21(80.8\%) out of 26 in treatment group and 10(43.5\%) out of 23 in control group, the findings are statistically significant $(\boldsymbol{P}<0.01)$.

Prognosis were assessed clinically by developmental assessment and neurosonogram at 3 months. These results were consistent with the previous studies done by Zhu et $\mathrm{al}^{16}$ where the neurological outcome were assessed at 18 months of age using Thompson neurological assessment and Elmahdy et $\mathrm{al}^{18}$ where the neurological outcome were assessed at 6 month of age using Denver Developmental Screening Test. In our study due to time constraint the clinical developmental assessment was used for early assessment of neurological outcome at the end of 3 months.

Elmahdy et $\mathrm{al}^{18}$ found normal EEG backgrounds, compared with control infants with HIE 10 vs 3 infants $(\boldsymbol{P}=0.010)$. In our study due to financial constraints small number of patient were able to perform EEG therefore we could not compare it statistically.

Erythropoietin had no effect in reducing the mortality rate, but the rate of disability was reduced. Neurological abnormality showed $56.5 \%$ in control group and $19.2 \%$ in intervention group $(p=.008)$ at 3 months. This is analogous to the results noted after head cooling, which reduced significantly the rate of disability. ${ }^{20}$

The role of Epo and its receptor in the brain has been widely 
studied in multiple preclinical models ranging from neonatal brain injury to adult injuries. Both Epo and Epo-analogs may prove useful for treating pathologies of the central nervous system. In neonates, the side effect profile of erythropoietin has been minimal. Treated infants have not shown common side effects seen in adults such as thrombosis and polycythemia. ${ }^{21}$

The study findings could have important implications on a child survival program in tertiary level hospital.

\section{Conclusion}

This study demonstrated the feasibility and potential efficacy of the use of human recombinant erythropoietin for term neonate with HIE. The use of rHuEPO was associated with promising clinical improvements, improved neuroimaging backgrounds and favorable neurodevelopmental outcomes at 3 months of age.

In this study we found that early administration of erythropoietin to neonate with moderate to severe HIE improves seizure control, early oral feeding, reduces hospital stay and better neurodevelopmental outcome at 3 months of age.

\section{References}

1. Black RE, Kelley L. Reducing perinatal and neonatal mortality. Child Health Research Project. Special Report 1999; 1-48.

2. Dixon G, Badawi N, Kurinczuk JJ, et al. Early developmental outcomes after newborn encephalopathy. Pediatrics2002;109:26-33

3. Robertson CM, Finer NN, Grace MG. School performance of survivors of neonatal encephalopathy associated with birth asphyxia at term. J Pediatr1989;114:753-760

4. Lorek A, Takei Y, Cady EB, Wyatt JS, Penrice J, Edwards AD, et al. Delayed ("secondary") cerebral energy failure after acute hypoxia-ischemia in the newborn piglet: continuous 48-hour studies by phosphorus magnetic resonance spectroscopy. Pediatr Res. 1994;36(6):699-706.

5. Gunn AJ, Gunn TR, de Haan HH, Williams CE, Gluckman PD. Dramatic neuronal rescue with prolonged selective head cooling after ischemia in fetal lambs. J Clin Invest 1997; 99: 248- 56.

6. Roelfsema V, Bennet L, George S, Wu D, Guan J, Veerman M, et al. Window of opportunity of cerebral hypothermia for postischemic white matter injury in the near-term fetal sheep. J Cereb Blood Flow Metab 2004; 24: 877- 86.

7. Hobbs C, Thoresen M, Tucker A, Aquilina K, Chakkarapani E, Dingley J. Xenon and hypothermia combine additively, offering long-term functional and histopathologic neuroprotection after neonatal hypoxia/ischemia. Stroke 2008; 39: 1307- 13 .
8. Kittaka M, Giannotta SL, Zelman V, Correale JD, DeGiorgio CM, Weiss MH, et al. Attenuation of brain injury and reduction of neuron-specific enolase by nicardipine in systemic circulation following focal ischemia and reperfusion in a rat modelNeurosurg .1997; 87:731- 7.

9. Vannucci RC, Towfighi J, Vannucci SJ. Secondary energy failure after cerebral hypoxia-ischemia in the immature rat. J Cereb Blood Flow Metab 2004; 24: 1090- 7.

10. Van der Kooij MA, Groenendaal F, KavelaarsA ,Kavelaars A, Heijnen $\mathrm{CJ}$, Bel $F V$, et al. Neuroprotective properties and mechanisms of erythropoietin in in vitro and in vivo experimental models for hypoxia/ischemia. Brain Res Brain Res Rev 2008; 59: 22-33.

11. Sakanaka M, Wen TC, Matsuda S, Masuda S, Morishita E, Nagao M, et al. In vivo evidence that erythropoietin protects neurons from ischemic damage. Proc Natl AcadSci U S A 1998; 95: 4635-40.

12. Morishita E, Masuda S, Nagao M, Narita H, Nishida M, Kawashima N, et al. Erythropoietin receptor is expressed in rat hippocampal and cerebral cortical neurons, and erythropoietin prevents in vitro glutamate-induced neuronal death. Neuroscience 1997; 76: 105-16.

13. Sun Y, Calvert JW, Zhang JH. Neonatal hypoxia/ischemia is associated with decreased inflammatory mediators after erythropoietin administration. Stroke 2005; 36: 1672-8.

14. Sola A, Wen TC, Hamrick SE, Ferriero DM. Potential for protection and repair following injury to the developing brain: a role for erythropoietin. Pediatr Res.2005; 57: 110- 117.

15. Kumar P. The transcriptional activator hypoxia inducible factor 2 (HIF2/EPAS-1) regulates the oxygen-dependent expression of erythropoietin in cortical astrocytes. J Neurosci. 2006;26(37):9471-9481.

16. Zhu C, Kang W, Xu F, Cheng X, Zhang Z, JiaL, et al. Erythropoietin improved neurologic outcomes in newborns with hypoxic-ischemic encephalopathy. Pediatrics. 2009;124(2):218-226.

17. Pradeep KB, Pradeep GCM, Mallikarjuna HB, Prabha S. Role of erythropoietin in full term newbornswith moderate hypoxic ischemicencephalopathy-a pilot study. International Journal of Medical and Applied Sciences.2015;4(2):239247.

18. Elmahdy $\mathrm{H}$, El-Mashad AR, El-Bahrawy H, El-Gohary T, El-Barbary A, Aly H. Human recombinant erythropoietin in asphyxia neonatorum: pilot trial. Pediatrics. 2010;125(5):1135-1142.

19. Bhat MA, Charoo BA, Bhat JI, Ahmed SM, Ali SW, Mufti MUH. Magnesium Sulfate in Severe Perinatal Asphyxia:A Randomized, Placebo-Controlled Trial. PEDIATRICS. 2009;123(5):764-769.

20. Gluckman PD, Wyatt JS, Azzopardi D, Ballard R, EdwadsAD, Ferriero DM, et al. Selective head cooling with mild systemic hypothermia after neonatal encephalopathy: multicentre RCT. 2005 Lancet;365(9460): 663-705.

21. Rangarajan V, Juul SE. Erythropoietin: Emerging role of erythropoietin in neonatal neuroprotection.Pediatr Neurol.2014; 51(4): 481-488.

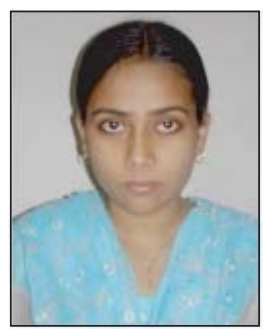

Dr. Syeda Mehnaz, passed MBBS from Sher-e-Bangla Medical College, Barisal. Then she achieved her MD (Paediatrics) from Bangladesh Institute of Child Health under Dhaka University. Now she is posted as a consultant of Paediatrics in 500 beded Kurmitola General Hospital, Dhaka,Bangladesh. 